rio de verdade 'socio-afetiva'109 em matéria de determinação dos laços de filiação, demonstram o afastamento de uma tendência pós-moderna no Projeto de Código Civil. Bem ao contrário do que já existe no Estatuto da Criança e do Adolescente (Lei 8.069/90), este sim voltado à disciplina de condutas e preocupado com as relações interpessoais inclusive de afeto ${ }^{110}$.

Mas se a concepção moderna é ainda prevalente no ordenamento jurídico positivo, à exceção de leis esparsas como a Lei 8.069/90 nos dispositivos que se referem à filiação, a nota da pós-modernidade tem sido verificada nas decisões contemporâneas dos colegiados, especialmente quando analisam o problema da paternidade. Notase que é crescente a discussão sobre a possibilidade de adoção da verdade socio-afetiva em matéria de investigação de paternidade, relativizando-se a sacralização do parentesco biológico ${ }^{111}$.

O mesmo, como constatado, segue verificado no acesso garantido pelos tribunais aos filhos da investigação da sua origem, independenmtemente do parentesco que exista no plano jurídico ${ }^{112}$. Garantem, assim, os tribunais a observação do requisito da individualidade presente no pós-modernismo e devidamente identificado por Erik Jayme nas relações de família. É em decisões colegiadas, mesmo que ainda isoladas, que se tem encontrado, no direito brasileiro, a ausência de uma preocupação da manutenção da família como instituição, voltando-se a preocupação do jurista para os indivíduos, nos vínculos que relacionam este grupo e nos direitos fundamentais de cada um, respeitados estes ainda que em

Impõe-se constatar, portanto, que os conceitos de pós-modernidade ainda com restrição restam-se integrados aos sistema jurídico brasileiro em matéria de filiação e mesmo no campo do Direito de Família. A adoção de normas narrativas, mais restritas Às leis especiais, e a manifestação de um maior individualismo na perspectiva do reconhecimento de direitos de origem apenas por meio jurisprudencial, revela ainda ser incipiente a aplicação de um conceito pós-moderno no sistema jurídico brasileiro. Mas, no mínimo, uma preocupação com os elementos da pós-modernidade já se encontra evidenciada no sistema posto. detrimento da unidade familiar.

109. A expressão utilizada pela doutrina para a identificação do estágio atual da concepção de uma paternidade. "Nós atravessamos três estágios no Direito brasileiro: o primeiro cogitava-se a verdade jurídica; o segundo estágio passou-se para a verdade biológica;(...) Um coito apenas determina para a vida inteira u parentesco, um coito entre pessoas que, às vezes, só tiveram aquele coito e nada mais! Desprezam-se anos e anos de convivência afetiva, de assistência, de companheirismo, de acompanhamento,

110. As determinaçōes normativas do art. 19 da Lei $8.069 / 90$, bem como as regras narrativas dos arts. 25 , relativas à família natural, e 33 , com relação à guarda de crianças e adolescentes.

111. Assim en trecho da decisão publicada na RJTJRS vol. 176, p. 772. "O que é que deve prevalecer afinal? A verdade biológica ou a verdade socio-afetiva? Parece que o ideal está na busca de um equilibrio das três verdades: da verdade jurídica, da verdade biológica e da verdade socio-afetiva. Mas a terceira, por enquanto, está sendo muito desprezada; em nome, do que eu diria, esta divinização do parentesco puramente biológico".

112. Neste sentido extrai-se da jurisprudência: "O perquirir sobre o quem é o pai biológico é direito personalissimo, imprescritivel, pouco importando que o investigante tenha sido adotado ou que tenha sido reconhecido pelo marido de sua mão, independendo de prévia propositura de ação visando nulificar o registro anterior que registra a paternidade ficta ou biológica" (voto do Des. Eliseu Gomes Torres, publicado na RJTJRS, vol. 176, p. 770).

Revista da Faculdade de Direito da UFRGS, v. 16, 1999

\section{Direito Constitucional Comparado e Constitucionalismo Brasileiro*}

\author{
Eduarda OKroeff EMachado Cassion \\ Professor Titular de Direito Constitucional da UFRGS
}

\section{Introdução}

D

esde sua origem, o constitucionalismo latino-americano sofreu forte influência do direito constitucional comparado, em especial do constitucionalismo europeu e do constitucionalismo norte-americano. Entretanto, enquanto que na Europa ou nos Estados Unidos da América do Norte o movimento constitucional traduziu em grande parte o projeto político dos setores modernos e urbanos da sociedade em sua luta contra o absolutismo e em defesa da liberdade, na América Latina e em especial no Brasil o movimento constitucional repercutiu os interesses dos setores tradicionais e agrários, protagonistas principais do processo de

Nesse sentido, as judiciosas palavras espanholas e portuguesa do NovoMundo, no início do séulo XIX, teve como conseqüência a difusão das emancipação nacional. de André Hauriou:

"A emancipação das colonias institutições políticas americanas. Mas aqui a vaga de Constituições desenvolve-se em meios claramente diferentes:

a) os países da América Latina mantém-se, mesmo após a proclamação de sua independência, como sociedades de estrutura francamente colonial. A vida política e sobretudo as assembléias são dominadas por oligarquias agrárias compostas de brancos ou de mestiços, que fazem e desfazem os governos;

b) afora os membros dessas oligarquias, a população rural é analfabeta, inculta, habituada a aceitar a dominação do grande proprietário rural;

c) todos os países da América Latina são de religião católica, enquadrados por um clero que se solidariza com as oligarquias agrária;

d) enfim, as tradições políticas da Espanha e de Portugal são favorá-
Trabalho apresentado no Simpósio "Dez Anos de Constituição: Cidadania ou Frustração?", realizado de 16 a 19 de setembro de 1998, em Curitiba, Paraná, promoção conjunta da OAB, IAB, CAHS, IDA e CPGD/UFPR. 
veis ao poder pessoal, o que, no quadro de instituições imitadas dos Estados Unidos, conduzirá a um desequilíbrio rápido dos poderes públicos em benefício do Executivo, a transmissões irregulares da autoridade e a freqüentes golpes de Estado; 0 presidencialismo latino-americano data dos inícios do século XIX."1

A visão unilinear de evolução das sociedades compromete a apreensão da realidade. Não se trata na nossa experiência de simplesmente estar-se em atraso, mas de construir-se $\mathrm{o}$ atraso. Na feliz expressão de Léo Hamon, deparamo-nos com "sociétés dyschrones", "... no sentido de que os sincronismos a que nossa história nos tinha habituado não se reencontram ..."2

Nosso constitucionalismo, ao contrá rio do constitucionalismo clássico, nasce sob o signo da autoridade. Aqui, as Constituições caracterizam-se antes por ser um estatuto da autoridade do que por constituírem um estatuto da liberdade. As relações entre o Príncipe e a Constituinte, entre o governante e a representação popular sempre foram problemáticas, a dissolução da Constituinte de 1823 por D. Pedro I significando um caso exemplar, embora extremo. Nossa primeira Constituição, Constituição de 1824, em última análise outorgada por D. Pedro I, inspira-se não no constitucionalismo revolucionário do combate ao absolutismo e da construção da liberdade, mas no constitucionalismo conservador da Restauração (1814-1830).
Haja vista a idéia e a realidade do Poder Moderador, a perturbar a separação dos poderes e a comprometer a afirmação da liberdade. Esta mesma Constituição desloca a Declaração dos Direitos, geralmente o preâmbulo das Constituiçōes da época, para o seu último e derradeiro artigo, o de número 179 do Título $8^{\circ}$ (Das Disposições Gerais e Garantias dos Direitos Civis e Políticos dos Cidadãos Brasileiros), as Constituições posteriores pouco alterando neste particular. De maneira geral, as idéias libertárias do constitucionalismo clássico, quando confrontadas com uma realidade diametralmente oposta àquela onde se originaram, desfiguraram-se em grande parte. No que se refere mais especificamente à organização do poder, observamos que nosso parlamentarismo monárquico correspondia melhor, inclusive com a criação do Poder Moderador, inspirado na obra de Benjamin Constant, à fórmula de Guizot ("o trono não é uma poltrona vazia") do que à fórmula de Thiers ("o Rei reina, mas não governa"). Aliás, Carlos Maximiliano assinalou enfaticamente que no Brasil o Rei reinava e governava. Lembre-se, entre outras coisas, o denominado "poder pessoal" do Imperador. O presidencialismo republicano, introduzido com a Constituição de 1891, representaria antes uma continuidade do que uma ruptura com este parlamentarismo monárquico, nossa instituição presidencial identificando-se praticamente com uma instituição imperial.

Se o liberal-conservadorismo predominou em grande parte de nossa história

1. In Droit Constitutionnel et Institutions Politiques, Éditions Montchrestien, Paris, 1972, pp. 73-74.

2. In Acteurs et Données de l'Histoire, PUF, Paris, 1970, t. 1, p.46. constitucional, retratado sobretudo nas Constituições de 1824, 1891 e 1946, encontramos igualmente uma outra vertente constitucional, a de autoritário-modernis mo, parecendo não ter havido espaço suficiente para a emergência de um liberalismo ao mesmo tempo modernizador e democrático. Liberalismo conservador e autoritarismo modernizador que nem sem pre se apresentam como tendências necessariamente contraditórias, a Constituição de 1934 alcançando talvez a melhor síntese das duas vertentes.

\section{A Constituição de 1988}

Até que ponto a nova Constituição conseguiu inovar com relação a nossa pre cária tradição constitucional e colocar-se, para o futuro, como instrumento de efetiva democratização da sociedade?

As Constituições costumam repre sentar nas democracias liberais um compro misso multifacetado: compromisso entre forças conservadoras e forças reformadoras compromisso entre as tradições jurídica existentes e o direito constitucional com parado, entre outros. Por isto mesmo, difi cilmente poderemos esperar ou exigir das Constituições o que elas não podem ou não devem oferecer, isto é uma perfeit homogeneidade ideológica ou política, em bora deva ser assegurada e preservada sua unidade e coerência jurídicas. A questão principal a ser respondida no nosso caso aquela referente a favor de qual projeto político ou ideológico operou-se prioritariamente esse compromisso.

Em que pesem os indiscutíveis avanços existentes no texto fundamental, o com promisso parece ter ocorrido favoravelmente, sobretudo se levarmos em conta a prática constitucional, ao

liberal-conservadorismo, que juntamente com o autoritário-modernismo são as duas principais vertentes de nossa história constitucional.

fato de o perfil da nova Constituição revelar-se predominantemente liberalconservador não impediu, porém, que novos e importantes direitos populares fossem previstos, atendendo inclusive ao caráter compromissório das Constituições. Assim, observamos alguns avanços significativos. A começar pela alternativa de redação de uma Constituição analítica, como tem sido a tendência contemporânea no direito constitucional comparado, evitando o equívoco conservador de elaboração de uma Constituição concisa, limitada apenas à declaração dos direitos, sobretudo os direitos individuais e os direitos políticos, e ao estatuto do poder, temas clássicos. Incorporando então novas questões que passaram a ter uma importância cada vez maior na atualidade, merecendo por isto mesmo um "status" constitucional. A declaração dos direitos, além de suceder ao preâmbulo e aos princípios fundamentais, alterando a sistemática adotada pelas Constituições brasileiras anteriores, amplia-se consideravelmente; mecanismos mais eficientes e aperfeiçoados de controle do poder foram alcançados; o fortalecimento do Legislativo, visado. Entretanto, pouco se alterou no atinente à ordem econômica, mantendo-se intacto o modo de acumulação vigente. Neste sentido, não se instrumentalizaram suficientemente aqueles direitos de forma a torná-los mais efetivos, além de simples 
declaração de intenções, tentativa permanente das elites. Além disto, tendeu-se a optar, em questões polêmicas e críticas, pelo subterfúgio ou pelo artifício de remeter a solução final da matéria ao legislador ordinário. O uso e o abuso das definições genéricas e vagas, das fórmulas vazias, das normas programáticas se pretendeu muitas vezes contornar conflitos e impasses políticos, evitando por exemplo os denominados "buracos negros", atendeu principalmente aos objetivos e interesses conservadores, comprometendo a eficácia jurídica e salientando ainda mais o caráter liberal-conservador da nova Constituição.

Identificamos nas modernas Constituições pelo menos três grandes segmentos: uma Constituição social, fundamentalmente a declaração dos direitos, tanto os clássicos e tradicionais, como os novos e modernos, uma Constituição política, basicamente a estrutura do poder, seja no plano horizontal (o sistema de governo), seja no plano vertical (a forma de Estado) e uma Constituição econômica, o modo de acumulação no essencial. Os avanços obtidos dizem prioritariamente respeito às duas primeiras, a Constituição econômica tendo sofrido inclusive alguns retrocessos.

A Constituição social inspirou-se em grande parte da Constituição portuguesa de 1976, embora tendo ainda ficado bastante aquém dela. Criaram-se novos institutos ou remodelaram-se anteriores institutos como a aplicabilidade imediata das normas definidoras dos direitos e garantias fundamentais, o mandado de injunção, a inconstitucionalidade por omissão, o mandado de segurança coletivo, o "habeas data", o direito a receber dos órgãos públicos infor- mações de interesse particular, coletivo ou geral, que serão prestadas no prazo da lei, sob pena de responsabilidade. Aliás, o artigo $5^{\circ}$, dos direitos e deveres individuais e cole tivos, talvez seja o ponto alto, mais libertário da nova Constituição. Introduziram-se mecanismos da democracia direta; alargaram se os direitos sociais. Rompeu-se parcialmente com a tradição individualista do nosso direito, entendendo-se os conflitos jurídicos não mais como exclusivamente inter-individuais, mas como cada vez mais como conflitos intergrupais, e reconhecendo-se o papel fundamental na atualidade dos novos sujeitos sociais como sindicatos, entidades e associações da sociedade civil. $\mathrm{O}$ presidencialismo foi reformado, fortalecendo-se o Legislativo, inclusive através da adoção de alguns corretivos parlamentaristas, sistemática aliás já inaugurada pela Constituição de 1934. Da mesmo forma, o Estado Federal foi redimensionado, alcançando-se talvez pela primeira vez uma efetiva autonomia municipal. Entretanto, no que se refere especificamente ao Poder Judiciário, não se chegou, conforme inicialmente cogitado, tanto à criação de uma verdadeira Corte Constitucional, nos moldes europeus, como à organização de um Conselho Nacional de Justiça, de ampla representação, que significariam um inequívoco progresso. Além disto, poucos avanços houve no sentido de um controle social do poder mais amplo, como a criação de um Conselho Econômico e Social. Os maiores atrasos estiveram por conta, porém, da Constituição econômica. Além de manter intacto o modo de acumulação vigente, retrocedeu-se nitidamente com relação à reforma agrária e ao papel do Estado na economia, ficando aquém mesmo do anterior estatuto autoritário.
Afinal, a nova Constituição antes serviu à legitimação da vontade das elites e à preservação do "status quo" ou poderá significar um instrumento de efetiva democratização da sociedade? A assinalarse, inicialmente, que o trabalho constituinte não se encerra propriamente com a promulgação da Constituição. A regulamentação do novo texto constitucional, assim como a adaptação da legislação ordinária, representam um prolongamento inevitável e necessário do processo constituinte. A maior ou menor amplitude dos direitos constitucionalmente previstos depende consideravelmente da atividade legislativa pós-constituinte. Além disso, a efetividade destes direitos depende igualmente da atuação dos partidos políticos e das entidades e associações da sociedade civil, bem como da consciência e da participação populares. Como vemos, a resposta àquela questão fica em grande parte em aberto. Independentemente das limitações apresentadas p.ela nova Constituição, cabe explorar ao máximo suas "virtualidades modernizantes".

\section{Conclusão}

A Constituição de 1988 representou um marco em nossa história constitucional. Participativa em seu processo de elabora- ção, democrática em seu conteúdo, incorporou avanços significativos do direito constitucional comparado.

Entretanto, inúmeras de suas conquistas permanecem fragilizadas por falta de legislação regulamentadora, por carência de normatividade infraconstitucional. Por outro lado, a prática constitucional tem concorrido para frustrar o espírito se não mesmo a letra do texto fundamental. Haja vista a experiência com relação às medidas provisórias, transformadas em instrumento habitual de governo, em método de governo mesmo.

Mais grave, tem sido a fúria reformista de sucessivos governos ávidos de uma enganosa rentabilidade ou eficiência máximas, mesmo se à custa do princípio de legalidade.

A ninguém é dado desconhecer que a Constituição deve continuamente adaptar-se, seja através de interpretação, seja através de modificação, às novas circunstâncias e necessidades impostas pelo decurso do tempo e pela evolução da sociedade. Entretanto, procura-se implementar, já de há muito, em sede de reforma da Constituição, na realidade uma nova Constituição, em flagrante desrespeito ao poder constituinte originário. 